\title{
(-) corterex \\ Preoperative administration of propranolol reduced the surgical risks of PHACES syndrome in a 14-month-old girl
}

\author{
Yuka Rokugo, Chiharu Ota, ${ }^{\oplus}$ Masato Kimura, Yoji Sasahara
}

Department of Pediatrics, Tohoku University School of Medicine, Sendai, Miyagi, Japan

Correspondence to Dr Chiharu Ota, chipaota@gmail.com

Accepted 20 March 2019

\section{Check for updates}

(c) BMJ Publishing Group Limited 2019. Re-use permitted under CC BY-NC. No commercial re-use. See rights and permissions. Published by BMJ.

To cite: Rokugo Y, Ota C, Kimura $\mathrm{M}$, et al. BMJ Case Rep 2019;12:e228117. doi:10.1136/bcr-2018228117

\section{SUMMARY}

PHACES syndrome is an uncommon neurocutaneous disorder first identified in 1996. Patients with PHACES syndrome often require surgical treatment for their anomalies, including intracranial vasculopathy, coarctation/interruption of the aorta, intracardiac defects, glaucoma/cataract and sternal defects. Risk factors associated with the symptoms of intraoperative/ perioperative management include ischaemic stroke due to the cerebral vasculopathy, airway obstruction due to the subglottic/tracheal haemangiomas and massive bleeding due to the large haemangiomas. Recently, propranolol is considered as first-line therapy for patients with infantile haemangiomas (IHs). However, until now, there have been no reported cases of PHACES syndrome treated by propranolol to reduce the surgical risks associated with $\mathrm{IH}$. In this report, we describe a case of a 14-month-old Japanese girl with PHACES syndrome treated by propranolol for IH before surgical closure of the ventricular septum defect. Oral administration of propranolol was effective in decreasing the size of $\mathrm{IH}$, leading to the uneventful perioperative course.

\section{BACKGROUND}

PHACES syndrome is an uncommon neurocutaneous disorder first identified by Frieden et al in 1996. ${ }^{1}$ PHACES syndrome includes posterior fossa malformations, segmental haemangiomas of the face, arterial anomalies, coarctation of the aorta/ cardiac defects, eye abnormalities, sternal cleft and/ or supraumbilical raphe. ${ }^{2}$ Patients with PHACES syndrome often require surgical treatment for their anomalies, ${ }^{2}$ including intracranial vasculopathy, coarctation/interruption of the aorta, intracardiac defects, glaucoma/cataract and sternal defects. ${ }^{3}$ Risk factors associated with the symptoms of intraoperative/perioperative management include ischaemic stroke due to the cerebral vasculopathy, ${ }^{4}$ airway obstruction due to the subglottic/tracheal haemangiomas $^{5}$ and massive bleeding due to the large haemangiomas. ${ }^{6}$ In 2008 , a non-selective $\beta$-blocker, propranolol, was reported to attenuate severe infantile haemangioma $(\mathrm{IH})^{7}$ and is now considered as first-line therapy for patients with $\mathrm{IH} .{ }^{2}$ However, until now, there have been no reported cases of PHACES syndrome treated by propranolol to reduce the surgical risks associated with $\mathrm{IH}$. Here, we describe a case of a 14-month-old Japanese girl with PHACES syndrome treated by propranolol for
IH before surgical closure of the ventricular septum defect (VSD). Oral administration of propranolol was effective in decreasing the $\mathrm{IH}$, leading to the uneventful perioperative course.

\section{CASE PRESENTATION}

A 14-month-old Japanese girl was admitted to our hospital to undergo surgical closure of a VSD. She was born at a regional hospital as a dichorionic diamniotic twin at 36 weeks gestation with a birth weight of $1900 \mathrm{~g}$. At birth, she had a small area of erythema on her right preauricular and upper lip area, which grew into a segmental haemangioma (figure 1A, left) within 3 weeks. A VSD was detected on a transthoracic echocardiogram (figure $1 \mathrm{~B}$ ). She was referred to our university hospital from the regional hospital for management of the growing haemangioma and VSD.

\section{INVESTIGATIONS}

MRI revealed cervical haemangioma and hypoplasia of the right cerebellar hemisphere without any signs of subglottic/tracheal haemangiomas (figure 2A). No cerebral arterial abnormalities were found by MRI angiography (figure 2B). She also showed sternal hypoplasia. Considering the combination of the segmental face haemangioma $>5 \mathrm{~cm}$ (major criterion), posterior fossa malformations (major criterion), intracardiac anomaly (minor criterion) and sternal dysplasia (major criterion), we diagnosed her with definite PHACES syndrome. ${ }^{2}$

\section{TREATMENT}

For treatment of the facial and cervical haemangiomas, oral administration of propranolol was started at $0.5 \mathrm{mg} / \mathrm{kg} /$ day and was gradually increased to $2.5 \mathrm{mg}$ $\mathrm{kg} /$ day without any adverse reactions. Repeated MRI at 2 weeks (figure 2C) and 7 months (figure 2D) after the initial treatment showed a significant reduction in the size of the cervical haemangioma. The size and colouring of the facial haemangioma were also markedly reduced within 7 months (figure $1 \mathrm{~A}$, middle). At 12 months of age, surgical closure of the VSD was planned based on the results from a right cardiac catheterisation, which showed a mean pulmonary arterial pressure of $32 \mathrm{~mm} \mathrm{Hg}$ and a pulmonary to systemic flow ratio of 2.2.

On admission at 14 months old, the patient weighed $7170 \mathrm{~g}(-2.3 \mathrm{SD})$ and was $70.8 \mathrm{~cm}(-1.8 \mathrm{SD})$ tall (figure 1C shows a growth chart). There were residual 

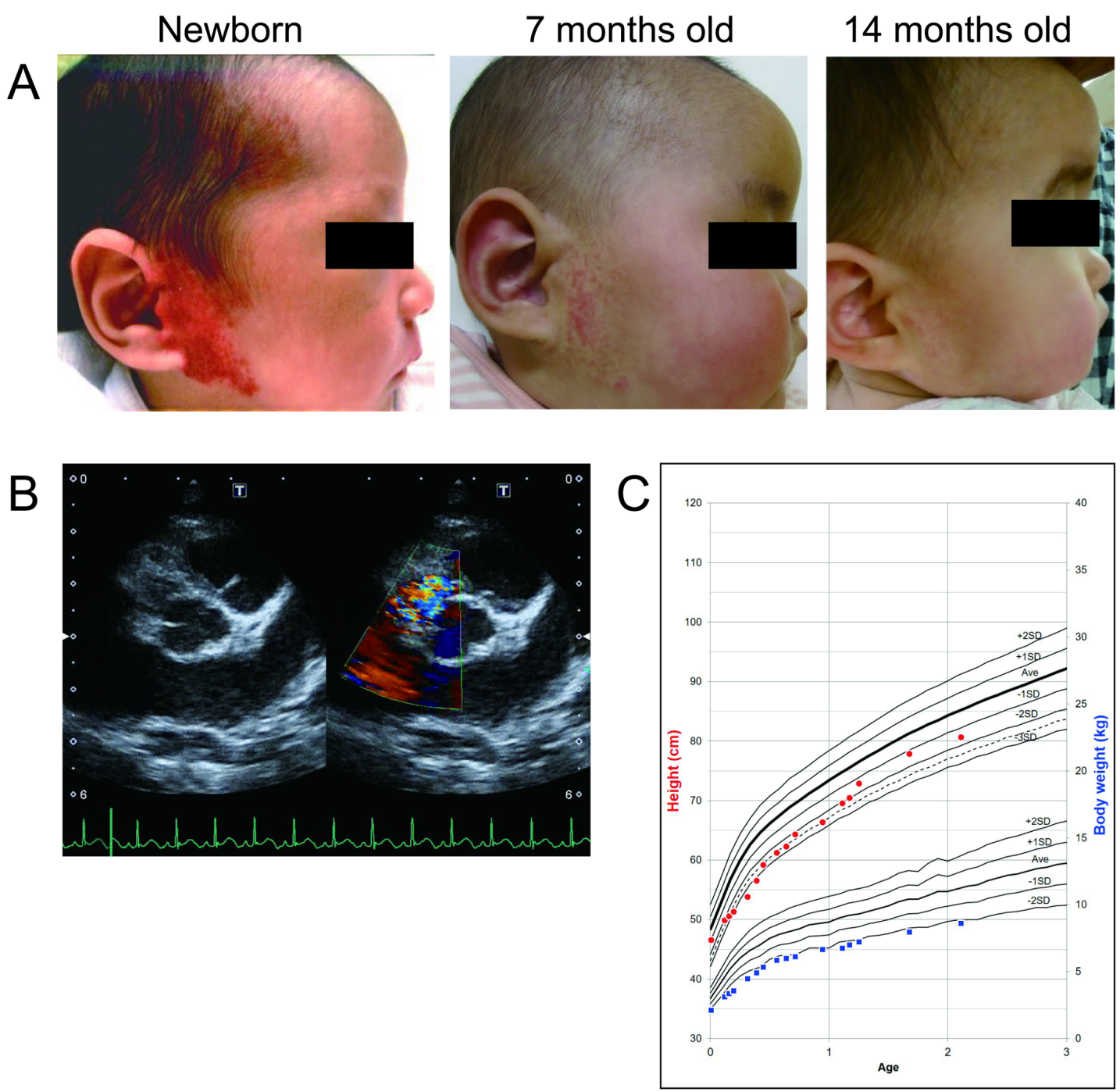

Figure 1 (A) Large facial haemangioma in the newborn period (left) and the regression of the haemangioma with propranolol treatment at 7 months old (in the middle) and 14 months old (left). (B) Transthoracic echocardiogram at 14 months shows perimembranous VSD. (C) A growth chart with centiles in the patient.

small haemangiomas on her right preauricular and upper lip area (figure 1A, right). A systolic murmur, classified as grade III/VI according to Levine's grading system, was audible at the left second parasternal area. The patient did not have audible rales, and her mental and physical development was within the normal range. The laboratory tests revealed a relatively low haemoglobin level $(106 \mathrm{~g} / \mathrm{L})$ with a normal platelet count $\left(556 \times 10^{9} / \mathrm{L}\right)$ and normal coagulation score. The hormonal examination results showed no evidence of endocrinological diseases. MRI revealed a further reduction in the size of cervical haemangioma (figure $2 \mathrm{E}$ ).

The VSD closure was performed under general anaesthesia without any complication, including ischaemic stroke, airway obstruction or massive bleeding of haemangioma. Total cardiopulmonary bypass (CPB) was done in $103 \mathrm{~min}$ with $49 \mathrm{~min}$ of aortic cross clamping.

\section{OUTCOME AND FOLLOW-UP}

The patient was safely extubated on the day of surgery. The perioperative course was uneventful without any growth of facial haemangioma nor any neurological complications, such as convulsion, paralysis or altered level of consciousness. In addition, MRI performed 10 days after surgery showed that the size of the cervical haemangioma did not increase (figure 2F) and that there were no signs of brain ischaemia. The patient was discharged from our facility on postoperative day 11 .

\section{DISCUSSION}

The prognosis of patients with PHACES syndrome is variable and depends on comorbidities, such as IH and cardiovascular and/ or cerebral artery abnormalities. Since patients with PHACES syndrome frequently require surgery for comorbidities, it is critically important to evaluate perioperative risk factors, including anaesthetic management and postoperative care. Severe $\mathrm{IH}$ has been reported to cause life-threatening events, including airway obstruction due to oropharyngeal $\mathrm{IH}^{5}{ }^{5}$ ulceration and massive bleeding of the large segmental $\mathrm{IH}^{6}$ and disseminated intravascular coagulation due to a large visceral $\mathrm{IH}$ that grew larger after cardiac surgery with $\mathrm{CPB} .{ }^{8}$ These events may have been avoidable if the severe IH had been reduced before surgery. In our case, we treated the patient with propranolol preoperatively to reduce the size of the large $\mathrm{IH}$ and safely performed cardiac surgery with $\mathrm{CPB}$. We believe that propranolol treatment for severe $\mathrm{IH}$ is one strategy to reduce the predicted perioperative risks of PHACES syndrome or other diseases with large IH. 

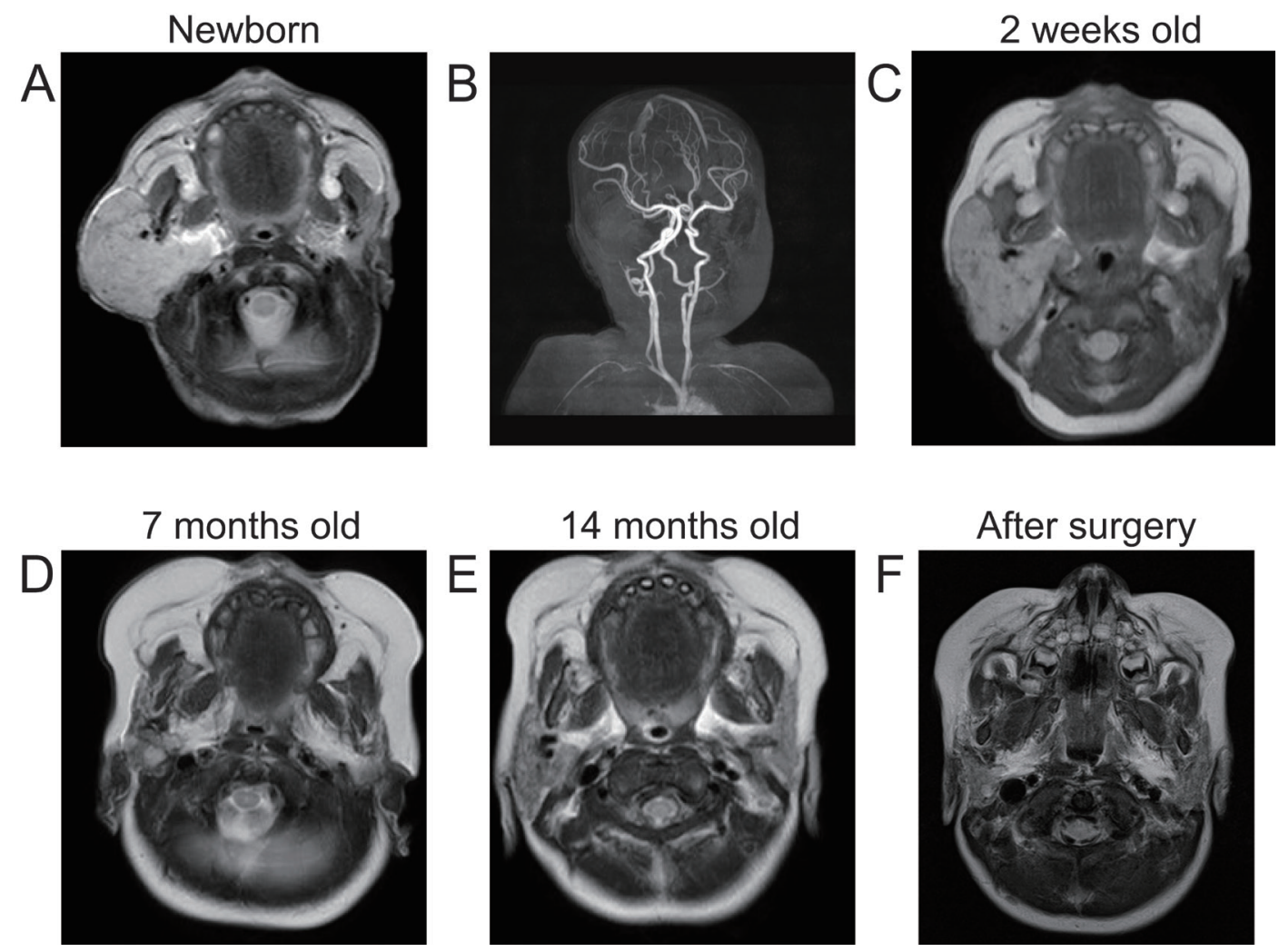

Figure 2 (A) Large cervical haemangioma in the newborn period. (B) MRI angiography for the evaluation of cerebral arterial abnormalities. (C)-(F) Regression of cervical haemangioma after propranolol treatment at (C) 2 weeks, (D) 7 months and (E) 14 months on admission, and (F) after VSD closure.

In contrast, several side effects of propranolol treatment for IH have been reported, including hypotension, bradycardia, hypoglycaemia, hypokalaemia, bronchoconstriction, stroke and ischemia, due to decreased arterial perfusion pressure. ${ }^{4}$ In patients with PHACES syndrome and cerebral arterial abnormalities, it is especially important to maintain cerebral perfusion pressure. Furthermore, perioperative physiological stress is a potential risk factor for strokes and seizures. It is essential to examine cerebral arterial abnormalities, including cerebral perfusion, and to check the endocrinological status, including thyroid function, glucose tolerance and electrolyte balance, before starting propranolol for IH. Appropriate guidelines for the perioperative management of patients with PHACES syndrome are needed.

In conclusion, we treated a patient with PHACES syndrome and severe IH with propranolol, which resulted in a prominent reduction of the $\mathrm{IH}$. The perioperative course of the subsequent intracardiac repair surgery was safe and uneventful.

The English in this document has been checked by at least two professional editors, both native speakers of English. For a certificate, please see: http://www.textcheck.com/certificate/zZ4gaY.

\section{Learning points}

- Patients with PHACES syndrome often require surgical treatment for their anomalies.

- Preoperative management of severe infantile haemangioma by oral propranolol would reduce the surgical risks of the PHACES syndrome.
Contributors YR wrote the manuscript and collected the data. CO designed and edited the manuscript. MK edited the manuscript. YS served as a scientific adviser.

Funding The authors have not declared a specific grant for this research from any funding agency in the public, commercial or not-for-profit sectors.

Competing interests None declared.

Patient consent for publication Parental/guardian consent obtained.

Provenance and peer review Not commissioned; externally peer reviewed.

Open access This is an open access article distributed in accordance with the Creative Commons Attribution Non Commercial (CC BY-NC 4.0) license, which permits others to distribute, remix, adapt, build upon this work non-commercially, and license their derivative works on different terms, provided the original work is properly cited and the use is non-commercial. See: http://creativecommons.org/ licenses/by-nc/4.0/

\section{REFERENCES}

1 Frieden IJ, Reese V, Cohen D. PHACE syndrome. The association of posterior fossa brain malformations, hemangiomas, arterial anomalies, coarctation of the aorta and cardiac defects, and eye abnormalities. Arch Dermatol 1996;132:307-11.

2 Garzon MC, Epstein LG, Heyer GL, et al. PHACE Syndrome: Consensus-derived diagnosis and care recommendations. J Pediatr 2016;178:24-33.

3 Molinaro F, Garzi A, Cerchia E, et al. Sternal reconstruction by extracellular matrix: a rare case of phaces syndrome. Open Med 2016;11:196-9.

4 McVey MJ, Farlinger CM, Van Arsdell G, et al. Anesthesia for complex cardiovascular surgery in a patient with PHACES Syndrome and Review of the Literature. $J$ Cardiothorac Vasc Anesth 2017;31:1042-7.

5 Shah MS, Verghese ST. When faced with anesthetizing an infant with PHACE syndrome: Watch out for an airway-occluding subglottic hemangioma!. A A Case Rep 2017:9:334-5.

6 Connelly EA, Viera M, Price C, et al. Segmental hemangioma of infancy complicated by life-threatening arterial bleed. Pediatr Dermatol 2009;26:469-72.

7 Léauté-Labrèze C, Dumas de la Roque $\mathrm{E}$, Hubiche T, et al. Propranolol for severe hemangiomas of infancy. N Engl J Med 2008;358:2649-51.

8 Kaori Matsumura MS, Mitsuyasu T, Moriyama M, et al. Seiji Nakamura A case of PHASES syndrome (written in Japanese). Japanese Journal of Oral \& Maxillofacial Surgery 2011;57:21-4. 
Copyright 2019 BMJ Publishing Group. All rights reserved. For permission to reuse any of this content visit https://www.bmj.com/company/products-services/rights-and-licensing/permissions/

BMJ Case Report Fellows may re-use this article for personal use and teaching without any further permission.

Become a Fellow of BMJ Case Reports today and you can:

- Submit as many cases as you like

- Enjoy fast sympathetic peer review and rapid publication of accepted articles

- Access all the published articles

Re-use any of the published material for personal use and teaching without further permission

Customer Service

If you have any further queries about your subscription, please contact our customer services team on +44 (0) 2071111105 or via email at support@bmj.com.

Visit casereports.bmj.com for more articles like this and to become a Fellow 